\title{
Migration of Phthalate-based Plasticizers from PVC and non-PVC Containers and Medical Devices
}

\author{
Marlei Veiga, Denise Bohrer,* Paulo C. Nascimento, Adrian G. Ramirez, \\ Leandro M. Carvalho and Regina Binotto
}

\author{
Departamento de Química, Universidade Federal de Santa Maria, Av. Roraima No. 1000, \\ 97105-900 Santa Maria-RS, Brazil
}

\begin{abstract}
A presença de cinco plastificantes derivados de ftalatos em equipamentos para administração intravenosa de soluções e em hemodialisadores (HD), que são feitos tanto de policloreto de vinila (PVC) quanto de outros materiais poliméricos, foi investigada. Destes ftalatos, o único autorizado por agências reguladoras é o di-(2-etilhexil) ftalato (DEHP) em equipamentos de PVC. A determinação foi feita por chromatografia líquida de alta eficiência (HPLC) com detecção UV. Os resultados mostraram que as bolsas para infusão que são feitas tanto de PVC quanto de etil vinil acetato (EVA) contêm apenas DEHP. Entretanto, as mangueiras dos equipos de infusão e dos $\mathrm{HD}$, bem como as fibras capilares dos HD feitas de celulose, contêm não só DEHP, mas também ftalato de dibutila (DBP). Todos os cinco ftalatos investigados foram encontrados nos capilares dos HD feitos de polisulfona. A migração de DEHP para soluções (aminoácidos, glicose e salina) armazenadas em bolsas ocorreu com taxas diferentes para os dois polímeros. Enquanto que para as bolsas de PVC o DEHP foi encontrado em soluções já nos primeiros dias de contato, para as bolsas de EVA a migração iniciou após aproximadamente 6 meses de armazenamento. Como os dispositivos analisados, com exceção das bolsas, contém, além do DHEP, outros ftalatos, o risco posto aos pacientes deve ser motivo de preocupação.
\end{abstract}

The presence of five plasticizer phthalates in bags and sets for intravenous administration and hemodialyzers (HD), which are made of polyvinyl chloride (PVC) and of other polymeric materials, was investigated. Di-(2-ethylhexyl) phthalate (DEHP) in PVC is the only authorized phthalate by regulatory agencies. Phthalate determination was carried out by high resolution liquid chromatograph (HPLC) with UV detection. The results showed that the infusion bags that are made of both PVC and ethylene vinyl acetate (EVA) contained only DEHP. In contrast, the tubing of infusion sets and of HD (as well as the cellulose capillaries of HD) contained not only DEHP but also dibutyl phthalate (DBP). Moreover, all five investigated phthalates were found in HD polysulfone capillaries. Migration of DEHP into the stored solutions (amino acids, glucose and saline) in bags occurred at different rates from one polymer to another. While DEHP from PVC bags was found in solutions within the first days of contact, the migration from EVA bags started only after approximately 6 months of solution storage. Since PVC and non-PVC devices (as well as capillaries of HD sets) contain DEHP and other phthalate-based plasticizers, the extent of the risk that they pose to patients remains a matter of concern.

Keywords: phthalates, infusion sets, hemodializers, PVC bags, EVA bags

\section{Introduction}

It is well known that medical devices that are made of polyvinyl chloride (PVC) may leach di-(2-ethylhexyl) phthalate (DEHP). DEHP is a plasticizer that is used to make the polymer flexible, depending on the substance in contact with the plastic material. Because of this,

*e-mail: ndenise@quimica.ufsm.br transfer tubing, transfusion sets and blood bags have been intensively examined as sources of DEHP ${ }^{1-7}$ and other kinds of polymers have been proposed as packaging material for pharmaceutical formulations. ${ }^{8,9}$ The presence and the release of DEHP have been also investigated in extracorporeal circulation circuits such as hemodialyzers ${ }^{10}$ and extracorporeal membranes of oxygenation circuits. ${ }^{11,12}$ Concerns are related to the potential health hazards that are associated with the release of DEHP from devices made of 
PVC. DEHP and its metabolites are known to impair the fertility of male rodents, and therefore it is assumed that they will affect human fertility as well. ${ }^{13}$

DEHP is an authorized additive for PVC and its concentration in the polymer mass is limited by Pharmacopoeias ${ }^{14,15}$ to $40 \%$. In spite of this, limits for DEHP in formulations that are stored in PVC bags are not establish in the pharmacopeial compendia. The only prescribed test is for DEHP that was extracted by the action of ether on PVC and proposes not to exceed $40 \%$ of the polymer mass.

Although PVC is the only allowed polymer to contain DEHP as a plasticizer, studies have shown that non-PVC plastic containers and devices also contain the plasticizer, resulting in the release of some DEHP. Sautou-Miranda et al. ${ }^{16}$ showed that DEHP rapidly leaches from co-extruded and triple-layered IV tubing into etoposide infusion solution. In this case, the external layer of the tubing material was of PVC and the internal part (in contact with the infusion) of polyethylene. While $51.67 \pm 3.63 \mu \mathrm{g} \mathrm{mL}^{-1}$ of DHEP were leached from the PVC tubing in $1 \mathrm{~h}$ of contact, only a slightly lower amount $\left(39.85 \pm 0.49 \mu \mathrm{g} \mathrm{mL}^{-1}\right)$ was leached from the triple-layered tubing.

The U. S. Food and Drug Administration (US-FDA) launched a non-regulatory publication, ${ }^{17}$ in which concerns about DEHP toxicity are discussed. The study concluded that there is little to no risk for patients that are exposed to the amount of released DEHP from PVC bags following the infusion of salts (normal saline or Ringer's solution). However, there is a small risk when considered the exposition to DEHP released from PVC bags which are used to store and administer drugs and require vehicle for solubilization.

In fact, other studies have shown that, depending on the constituents in the formulation, the extractable DEHP can be much higher than expected. The migration process is governed by the nature of the formulation because of the apolar character of DEHP and the absence of chemical bonds between the polymer and the plasticizer. While DEHP concentration was not higher than $24 \mu \mathrm{g} \mathrm{L}^{-1}$ in 14 months in saline solutions, the DEHP amount reached over $300 \mu \mathrm{g} \mathrm{L}^{-1}$ in $2 \mathrm{~h}$ in oily vehicles. ${ }^{18}$

Although DEHP is the only allowed plasticizer for PVC, other phthalates may have been used either in PVC or non-PVC medical devices. Diethyl phthalate (DEP) ${ }^{19}$ is used as plasticizer for cellulose ester plastic films and sheets, also in adhesive plasticizers and surface lubricants that are used in food and pharmaceutical packaging. Butyl benzyl phthalate (BBP) is a plasticizer for polymers such as polyvinyl acetate, polyurethane and cellulose,${ }^{20}$ to cite only three among a family of more than 10 members.
Wahl et $a l .{ }^{21}$ identified DEHP, dihexyl phthalate (DHP), diisobutyl phthalate (DIBP), dibutyl phthalate (DBP) and butyl 2-ethylhexyl phthalate (BEP) in infusion and dialysis tubing and infusion bags, being DEHP the most abundant plasticizer in all devices. However, while blood storage bags contained only DEHP, at least three different phthalates (DEP, DBP and DIBP) were detected in all other studies.

More recently, the European Chemical Agency (ECHA) recommended that seven chemical substances of very high concern should not be used without specific authorization. They are all used in products to which consumers and workers are exposed. Among them, three phthalates (DEHP, BBP and DBP) were selected due to their impairment of reproduction. ${ }^{22}$ The Scientific Committee on Health and Environmental Risks (SCHER) of the European Union launched non-regulatory publications on the presence of phthalates in school supplies. ${ }^{23}$ They concluded that phthalates in school supplies are below the tolerable daily intake (TDI), but DEHP may exceed the TDI in other population groups, as those exposed to other plastic apparatus such as medical devices. ${ }^{23}$

In this study, we compared PVC and EVA bags, as well as the tubing of the administration set, in their capability of leaching DEHP, and four other parent phthalates into the solutions of parenteral nutrition components. We also investigated the possibility of hemodialyzers (tubing and capillaries) as a source of DEHP and other phthalates for patients undergoing hemodialysis. For both devices, the concern was not only the presence of the phthalates in the packaging material but also the role of the time of contact during shelf-life and use on the leaching of the plasticizers.

\section{Material and Methods}

\section{Chromatographic separation}

The chromatographic equipment consisted of a DX-300 gradient chromatographic system (Dionex, Sunnyvale, USA) with UV detector (Shimadzu, Kyoto, Japan) and a C-R6A data processor (Shimadzu), and a Supercosil LC-18 $(150 \times 4.6 \mathrm{~mm}, 5 \mu \mathrm{m})$ column. Two different chromatographic conditions were used: one for the determination of the five phthalates and another for the determination of DEHP alone. For the separation of the five phthalates, the eluent consisted of acetonitrile:water in a proportion of 94:6 (v/v) and a flow rate gradient was used. The system started at $0.5 \mathrm{~mL} \mathrm{~min}^{-1}$ and this flow rate was kept for $15 \mathrm{~min}$. After this, it increased to $1.0 \mathrm{~mL} \mathrm{~min}^{-1}$ and stayed at this level up to the end of the chromatographic run. The measurement was carried out at $202 \mathrm{~nm}$ and a sample loop of $25 \mu \mathrm{L}$ was used. For the determination of 
DEHP alone, the mobile phase was acetonitrile:methanol $(9: 1, \mathrm{v} / \mathrm{v})$ at a flow rate of $0.8 \mathrm{~mL} \mathrm{~min}^{-1}$ without gradient. ${ }^{24,25}$ The measurement was carried out at $220 \mathrm{~nm}$ and a sample loop of $20 \mu \mathrm{L}$ was used. A blank sample (hexane) was injected 6 times to calculate the limit of detection (LOD).

\section{Reagents}

Standard solutions of diethylhexyl phthalate (DEHP), dibutyl phthalate (DBP), dimethyl phthalate (DMP), diethyl phthalate (DEP) and butylbenzyl phthalate (BBP) (Sigma, St. Louis, USA) were prepared by convenient dilution of a stock solution containing $1 \mathrm{mg} \mathrm{mL}^{-1}$ in methanol. Acetonitrile, methanol and n-hexane were all from Merck HPLC grade (Darmstadt, Germany). $\mathrm{NaCl}$, $\mathrm{KCl}, \mathrm{CaCl}_{2} .2 \mathrm{H}_{2} \mathrm{O}, \mathrm{MgCl}_{2} 6 \mathrm{H}_{2} \mathrm{O}, \mathrm{NaHCO}_{3}$, sodium acetate, glucose and albumin were all from Merck. The water was distilled, de-ionized and further purified using a Milli-Q high-purity water device (Millipore, Bedford, USA).

To avoid contamination, only laboratory glassware was used, previously washed with an ethanolic solution of $10 \%$ $\mathrm{HNO}_{3}$ in ethanol (v/v).

\section{Samples}

Samples consisted of new (empty) plastic infusion sets: PVC and EVA bags (Baxter) and burette (B. Braun), and hemodialyzers made of cellulose diacetate (CAHP/DICEA 150, Baxter) and polysulfone (Hemoflow FHHPS, Fresenius). CAPD bags (Baxter) were also analyzed, but in this case, the samples were collected from filled bags. Besides being used to test phthalate migration into the different solutions, these containers or devices were analyzed to determine the concentration of phthalates in the material itself.

Individual solutions of the amino acids, which are usually present in formulations for parenteral nutrition in a concentration of $0.5 \%(\mathrm{~m} / \mathrm{v})$, were stored in new PVC and EVA bags (250 mL). Purified water, $0.9 \% \mathrm{NaCl}$ and $10 \%$ glucose were also individually stored in both kinds of bags. The bags were let to stand at room temperature and aliquots of $1 \mathrm{~mL}$ were taken at time intervals of $15,45,75,105$, 165,225 and 365 days through the rubber septum using a glass syringe with a stainless steel needle. The samples were treated as described for the determination of DEHP.

Commercial dialysis concentrates and solutions for parenteral nutrition (all stored in plastic containers) were also analyzed for the determination of their level of contamination by DEHP. At least three samples from the same lot were analyzed. The analyzed samples were: $50 \%$ glucose, $0.9 \% \mathrm{NaCl}$, two $10 \%$ amino acid solutions, two lipid emulsions and two saline concentrates for hemodialysis (one acid and one basic). Pure hexane was used as a blank sample.

\section{Sample treatment}

Samples were prepared as described in the European Pharmacopoeia. ${ }^{7}$ For the analysis of solid samples (containers and devices), ca. $0.1 \mathrm{~g}$ of the material, which was previously cut into small pieces, was mixed with $2 \mathrm{~mL}$ hexane and shaken for $15 \mathrm{~min}$ in a horizontal shaker (Edmund Bühler, Hechingen, Germany).

Liquid samples were collected in glass tubes and stored at $4{ }^{\circ} \mathrm{C}$ until analysis. To $1 \mathrm{~mL}$ of each sample, $1 \mathrm{~mL}$ hexane was added and the mixture was vortexed for $10 \mathrm{~min}$. The organic layer was transferred to glass tubes and 20 or $25 \mu \mathrm{l}$ aliquot was injected into the chromatograph.

The extraction procedure was carried out with an aqueous sample that was spiked with the 5 analytes (2.5 $\mathrm{mg} \mathrm{L}^{-1}$ each) and this was repeated five times with new portions of hexane and all aliquots of hexane were injected into the chromatograph.

An extra test was carried out with the internal capillary of the HD. The dialyzers were dismounted and an amount of $c a .1 \mathrm{~g}$ of the capillary material was submersed in the pure dialysis solution (synthetic, made by dissolving the components in the usual concentration) and in the dialysis solution spiked with $4.86 \mathrm{mg} \mathrm{L}^{-1}$ DEHP. Aliquots of the fluids were collected after $1 \mathrm{~h}$ and 5 days of the submersion and analyzed for DEHP.

\section{Results and Discussion}

The chromatogram in Figure 1 shows that the separation of the phthalates (using the optimized conditions) occurred within a running time of $25 \mathrm{~min}$. The analytical curves for each phthalate and the respective figures of merit are given in Table 1. The method demonstrated to be well suited for the simultaneous determination of the 5 phthalates.

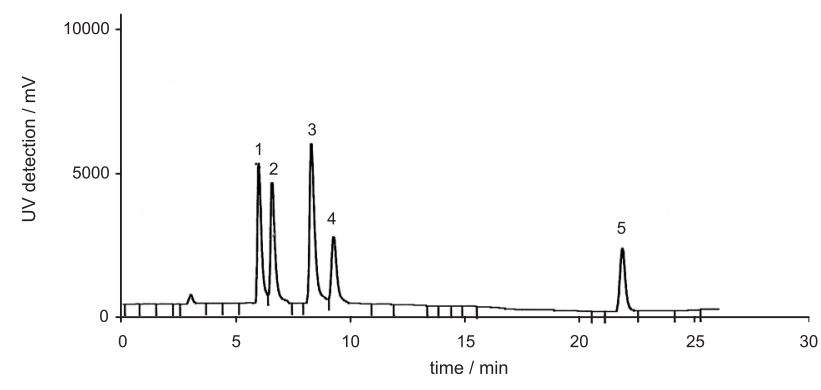

Figure 1. Chromatogram of a standard solution containing the phthalates: (1) DMP, (2) DEP, (3) DBP, (4) BBP, in a concentration of $0.25 \mathrm{mg} \mathrm{L}^{-1}$, and (5) DEHP in a concentration of $0.50 \mathrm{mg} \mathrm{L}^{-1}$. 
Table 1. Figures of merit of the simultaneous chromatographic determination of the four phthalates and of DEHP alone

\begin{tabular}{|c|c|c|c|c|c|}
\hline \multirow{2}{*}{ Parameter } & \multicolumn{5}{|c|}{ Phthalate } \\
\hline & DEHP & DMP & DEP & DBP & BBP \\
\hline Range / (mg L-1) & $0.50-10.00$ & $0.25-5.00$ & $0.25-5.00$ & $0.25-5.00$ & $0.25-5.00$ \\
\hline $\begin{array}{l}\text { Analytical curve } \\
\mathrm{y} \text { (peak area) } \\
\mathrm{x}(\text { conc. }) /\left(\mathrm{mg} \mathrm{L}^{-1}\right)\end{array}$ & $y=6013 x-108$ & $y=22833 x+2434$ & $y=22649 x+577$ & $y=29198 x+232$ & $y=11247 x+1619$ \\
\hline $\mathrm{R}^{2}$ & 0.994 & 0.998 & 0.998 & 0.999 & 0.997 \\
\hline $\mathrm{LOD} /\left(\mathrm{mg} \mathrm{L}^{-1}\right)$ & 0.05 & 0.01 & 0.01 & 0.01 & 0.03 \\
\hline Repeatability / \% & 1.4 & 1.5 & 0.7 & 0.9 & 1.6 \\
\hline Reproducibility $/ \%$ & 4.1 & 3.4 & 2.2 & 2.1 & 3.3 \\
\hline
\end{tabular}

${ }^{a} \mathrm{n}=6 ;{ }^{\mathrm{b}} \mathrm{n}=3 ; \mathrm{R}^{2}$ : linear correlation.

The yield of the extraction of spiked samples showed that more than $95 \%$ of the analytes are extracted in the first portion of hexane. Therefore, the procedure was carried out with one extraction step only.

Since only DEHP was found in some samples, the chromatographic system was set in order to determine DEHP only, in a shorter analysis time. ${ }^{24}$

Table 2 presents the amount of plasticizers in the investigated materials. Only DEHP was found in the obtained extracts from the bags. Although in low amounts, EVA bags also presented DEHP in their composition. On the other hand, the tubing material coupled to the bags and the burette presented DBP as well, although in much lower concentrations. Because the HD set contains two types of tubing, one softer than the other, both were analyzed. It is interesting to observe that the amount of DEHP in the softer tubing is at least five times higher than in the harder one. This is an expected result since plasticizers are added to make PVC more flexible. Surprisingly, both HD capillaries presented DEHP and DBP. Moreover, all other phthalates were found in the polysulfone capillary. However, while the sum of all extracted phthalates reached $5 \mathrm{mg} \mathrm{g}^{-1}$ in the polysulfone capillary, it was more than double (11.4 $\left.\mathrm{mg} \mathrm{g}^{-1}\right)$ in the cellulose capillary.

Since the usual shelf-life of infusion solutions is two years, migration rates of DEHP from PVC and EVA bags were measured for a period of 1 year using water and the solutions of $\mathrm{NaCl}$, amino acids and glucose as extractors. Attempts to store the pure components of the lipid emulsion were unsuccessful as the bag was damaged leading to the leak of the content.

Given that phthalates are very soluble in lipophylic vehicles, water soluble constituents were selected, but some apolar species were included. The results are presented in Figure 2. DEHP leached from EVA bags as much as for the PVC bags. Very low amounts were extracted by water and saline solutions from both kinds of bags. Among amino acids, differences were observed. For both kinds of polymers, histidine and threonine amino acids promoted the highest extraction rates. However a difference was observed in the kinetics of the migration. While the extraction for $\mathrm{PVC}$ gradually increased over time, the extraction rates for

Table 2. Amount of extracted phthalates from plastic materials used for intravenous infusion administration and from hemodialysis sets

\begin{tabular}{|c|c|c|c|c|c|c|c|}
\hline \multirow{2}{*}{ Product } & \multirow{2}{*}{ Origin } & \multirow{2}{*}{ Supplier } & \multicolumn{5}{|c|}{ Phthalate $\pm \mathrm{SD}^{\mathrm{a}} /\left(\mathrm{mg} \mathrm{g}^{-1}\right)$} \\
\hline & & & DEHP & DMP & DEP & DBP & $\mathrm{BBP}$ \\
\hline PVC bag $(500 \mathrm{~mL})$ & new empty bag & Baxter & $154 \pm 22$ & n.d. & n.d. & n.d. & n.d. \\
\hline EVA bag $(500 \mathrm{~mL})$ & new empty bag & Baxter & $2.86 \pm 0.44$ & n.d. & n.d. & n.d. & n.d. \\
\hline PVC bag (1000 mL) & lipid emulsion & Fresenius-Kabi & $170 \pm 25$ & n.d. & n.d. & n.d. & n.d. \\
\hline PVC bag (2000 mL) & CAPD dialysate & Baxter & $115 \pm 23$ & n.d. & n.d. & n.d. & n.d. \\
\hline Flexible tubing & infusion set (bag) & Baxter & $82.3 \pm 9.7$ & n.d. & n.d. & n.d. & n.d. \\
\hline Flexible tubing & burette & B. Braun & $73.3 \pm 8.7$ & n.d. & n.d. & $0.015 \pm 0.003$ & n.d. \\
\hline Flexible tubing & dialyzer & Baxter & $135 \pm 17$ & n.d. & n.d. & $0.024 \pm 0.005$ & n.d. \\
\hline Flexible tubing & dialyzer & Fresenius-Kabi & $163 \pm 21$ & n.d. & n.d. & $0.008 \pm 0.004$ & n.d. \\
\hline Rigid tubing & dialyzer & Baxter & $23.7 \pm 1.9$ & n.d. & n.d. & $0.055 \pm 0.009$ & n.d. \\
\hline Rigid tubing & dialyzer & Fresenius-Kabi & $17.8 \pm 2.0$ & n.d. & n.d. & n.d. & n.d. \\
\hline Capillary (cellulose) & dialyzer & Baxter & $11.3 \pm 2.3$ & n.d. & n.d. & $0.109 \pm 0.021$ & n.d. \\
\hline Capillary (polysulfone) & dialyzer & Fresenius-Kabi & $4.75 \pm 0.71$ & $0.031 \pm 0.011$ & $0.053 \pm 0.009$ & $0.022 \pm 0.010$ & $0.088 \pm 0.017$ \\
\hline
\end{tabular}

aSD: standard deviation $(\mathrm{n}=3)$; n.d.: not detected (below the limit of detection). 
EVA bags during the first 6 months were very low but after that increased considerably.

Despite the fact that the capillaries contain phthalates, it was supposed that they could also adsorb the circulating DEHP (from the PVC tubing) due to the nature of the
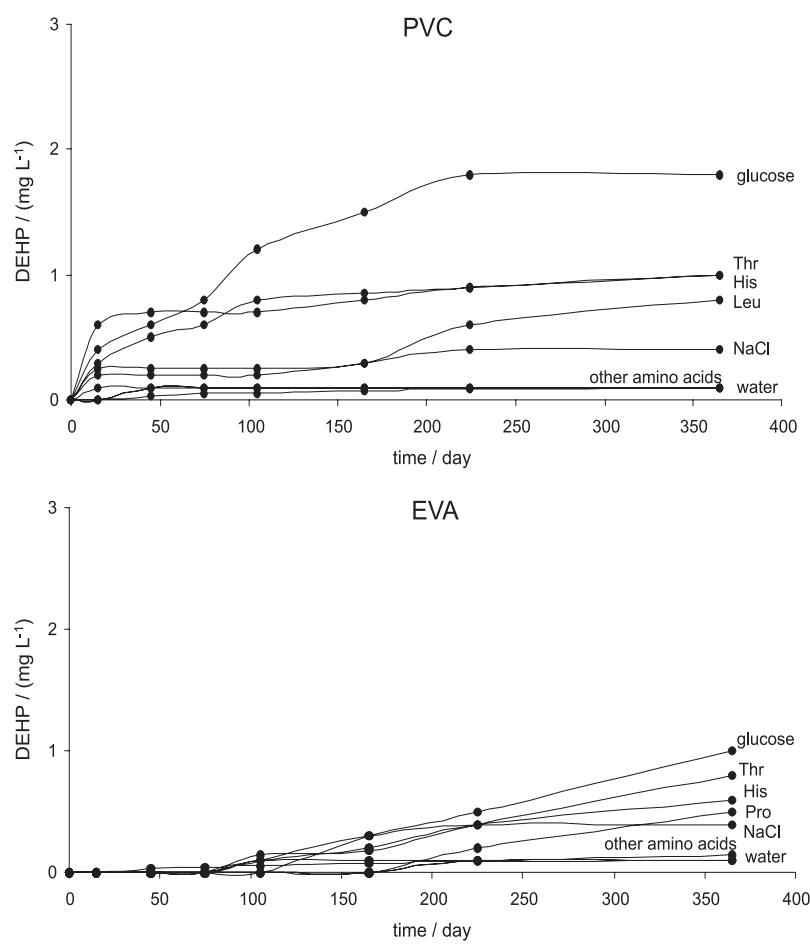

Figure 2. Extraction rates of DEHP from PVC and EVA bags in solutions of amino acids, $\mathrm{NaCl}$, glucose and pure water during a period of contact of a year. capillary material. To confirm the presence of DEHP in the capillaries and also their ability to adsorb the phthalate, the dialyzers were dismounted and an amount of $c a .1 \mathrm{~g}$ of the capillary material was submersed in the pure dialysate and in the dialysate spiked with DEHP. The results in Figure 3 clearly show that the phthalate can migrate from the capillary into the fluid or vice versa, depending on the concentration of DEHP in both phases. Being adsorbed on the capillary, it can be leached anytime thereafter depending on the concentration ratio between the solid and liquid phases.

Since the HD capillaries present a huge surface purposely to enhance the contact between blood and dialysate, a rough calculation was made to determine the amount of phthalates in the total mass of the capillary in the HD. Considering that each dialyzer contained $c a .25 \mathrm{~g}$ of the capillary material, the total amount of phthalates was $282 \mathrm{mg}$ in the cellulose dialyzers and $123 \mathrm{mg}$ in the polysulfone dialyzers.

To finalize this study, it was measured the concentration of phthalates in some commercial formulations. Table 3 presents the results for DEHP, as it was the only phthalate found in these samples. It is interesting to see that concentrates for hemodialysis, saline and glucose solutions (even stored in containers supposedly free of phthalates (polyethylene)) presented DEHP at some level. This contamination is probably not from the flasks or bottles where they are stored but from the tubing material that are used in their industrial preparation.

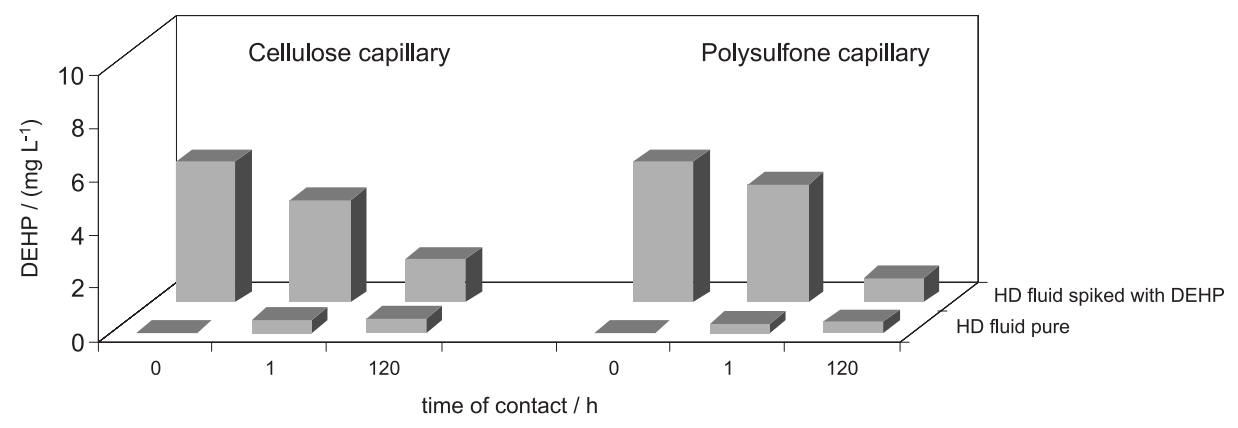

Figure 3. DEHP concentration in solution in which $1 \mathrm{~g}$ HD capillaries were submersed for $1 \mathrm{~h}$ and 5 days. Measurements were carried out using pure HD solution and a solution spiked with $4.86 \mathrm{mg} \mathrm{L}^{-1}$ DEHP.

Table 3 DEHP concentrations in products for parenteral administration and hemodialysis concentrates

\begin{tabular}{|c|c|c|c|}
\hline Sample & Packaging & Supplier & $\mathrm{DEHP} \pm \mathrm{SD}^{\mathrm{a}} /\left(\mathrm{mg} \mathrm{L}^{-1}\right)$ \\
\hline Amino acids & PVC bag & Fresenius-Kabi & $1.65 \pm 1.93$ \\
\hline Glucose $50 \%$ & PVC bottle & Fresenius-Kabi & $0.72 \pm 0.05$ \\
\hline $\mathrm{NaCl} 0.9 \%$ & PVC bottle & Fresenius-Kabi & $1.04 \pm 0.37$ \\
\hline Saline concentrate for hemodialysis (acid) & polyethylene bottle & Salbego & $0.91 \pm 0.05$ \\
\hline Saline concentrate for hemodialysis (basic) & polyethylene bottle & Salbego & $1.03 \pm 0.05$ \\
\hline
\end{tabular}

aSD: standard deviation $(\mathrm{n}=3)$. 


\section{Conclusions}

Although it was not expected, EVA bags also presented DEHP in their constitution. The other investigated phthalates were found neither in PVC nor in EVA bags. DEHP migration rates by the action of some amino acid, $\mathrm{NaCl}$ and glucose occurred to a larger extent than in pure water. The migration from EVA bags required a longer time of contact than from PVC bags since significant amounts of DEHP were found in solutions only after 6 months of storage. Although in low concentration, DBP was also found in the tubing material coupled to bags and burettes. Hemodialysis sets presented phthalates in all parts. The tubing material mostly contains DEHP, but the capillaries contained DEHP and other phthalates. Cellulose diacetate contained only DBP, but polysulfone all four. The possibility of DEHP migration through the capillary membranes into patient blood is difficult to evaluate, the reasons are: firstly, the internal tubing for blood circulation is also made of PVC and secondly, the capillaries themselves contain DEHP and other phthalate-based plasticizers. The risk extent that DEHP and other phthalates pose to patients is still a matter of concern. On the other hand, considering the frequency with which dialysis is used by chronic renal patients and the presence of these plasticizers in all parts of the HD set, physicians must be aware of adverse reactions to the patients.

\section{Acknowledgement}

The authors are grateful to the Brazilian agency $\mathrm{CNPq}$ (Conselho Nacional de Desenvolvimento Científico e Tecnológico) for scholarships.

\section{References}

1. Allwood, M. C.; Martin, H.; Int. J. Pharm. 1996, 127, 65.

2. Jenke, D.; PDA J. Pharm. Sci. Technol. 2002, 56, 332.

3. Loff, S.; Kabs, F.; Subotic, U.; Schaible, T.; Reinecke, R.; Langbein, M.; JPEN J. Parenter. Enteral Nutr. 2002, 26, 305.

4. Kambia, K.; Dine, T.; Gressier, B.; Bah, S.; Germe, A.-F.; Luyckx, M.; Brunet, C.; Michaud, L.; Gottrand, F.; Int. J. Pharm. 2003, 262, 83.

5. Jenke, D.; PDA J. Pharm. Sci. Technol. 2006, 60, 191.

6. Takehis, H.; Naoko, E.; Masahiko, S.; Katsuhide, T.; Moriyuki, O.; Keizoh, S.; Mutsuko, T.; Kenji, K.; Shinichiro, N.; Toshio, O.; Int. J. Pharm. 2005, 297, 30.

7. Loff, S.; Hannmann, T.; Subotic, U.; Reinecke, F. M.; Wischmann, H.; Brade, J.; J. Pediatr. Gastroenterol. Nutr. 2008, 47,81 .
8. Christensson, L.; Junggren, L.; Nilsson-Thorell, C.; Arge, B.; Diehl, U.; Hagstam, K. E.; Lundberg, M.; Int. J. Artif. Organs 1991, 14, 407.

9. Ito, R.; Miura, N.; Iguchi, H.; Nakamura, H.; Ushiro, M.; Wakui, N.; Nakahashi, K.; Iwasaki, Y.; Saito, K.; Suzuki, T.; Nakazawa, H.; Int. J. Pharm. 2008, 360, 91.

10. Faouzi, M. A.; Dine, T.; Gressier, B.; Kambia, K.; Luyckx, M.; Pagniez, D.; Brunet, C.; Cazin, M.; Belabed, A.; Cazin, J. C.; Int. J. Pharm. 1999, 180, 113.

11. Haishima, Y.; Matsuda, R.; Hayashi, Y.; Hasegawa, C.; Yagami, T.; Tsuchiya, T.; Int. J. Pharm. 2004, 274, 119.

12. Burkhart, H. M.; Joyner, N.; Niles, S.; Ploessl, J.; Everett, J.; Iannettoni, M.; Richenbacher, W.; ASAIO J. 2007, 53, 365.

13. Directorate General for Health \& Consumer Protection (DG SANCO) - European Commission; Opinion on Medical Devices containing DEHP Plasticized PVC: Neonates and other groups possibly at Risk from DEHP Toxicity, Doc. No. SANCO/ SCMPMD/2002/0010 Final, Europe, 2002.

14. European Pharmacopoeia, European Directorate for the Quality of Medicines (EDQM), $4^{\text {th }}$ ed., Strasbourg: France, 2004.

15. The United States Pharmacopeia Convention, The United States Pharmacopeia, USP 30, Rockville, 2008.

16. Sautou-Miranda, V.; Brigas, F.; Vanheerswynghels, S.; Chopineau, J.; Int. J. Pharm. 1999, 178, 77.

17. The U. S. Food and Drug Administration (US-FDA), Center for Devices and Radiological Health, Safety Assessment of Di2-ethylhexylphthalate (DEHP) Released from PVC Medical Devices, Rockville, 1999.

18. Arabin, A.; Jacobsson, S.; Hagman, A.; Östelius, J.; Int. J. Pharm. 1986, 28, 211.

19. World Health Organization (WHO), Diethyl Phthalate, Concise International Chemical Assessment Document 52, Geneva, 2003.

20. World Health Organization (WHO), Butyl Benzyl Phthalate, Concise International Chemical Assessment Document 17, Geneva, 1999.

21. Wahl, H. G.; Hoffmann, A.; Häring, H.-U.; Liebich, H. M.; J. Chromatogr., A 1999, 874, 1.

22. http://echa.europa.eu/doc/press/ni_09_07_first_ svhc_20090526.pdf accessed in March 2011.

23. Scientific Committee on Health and Environmental Risks (SCHER) - European Commission; Opinion on Phthalates in School Supplies, 2008

24. Aignasse, M. F.; Prognon, P.; Stachowicz, M.; Gheyouche, R.; Pradeau, D.; Int. J. Pharm. 1995, 113, 241.

25. Kambia, K.; Dine, T.; Gressier, B.; Germe, A.-F.; Luyckx, M.; Brunet, C.; Michaud, L.; Gottrand, F.; J. Chromatogr., B: Anal. Technol. Biomed. Life Sci. 2001, 755, 297.

Submitted: April 30, 2011

Published online: October 18, 2011 